\title{
O Festival Internacional de Cinema e Vídeo Ambiental (FICA) e a economia criativa
}

\author{
Gustavo Henrique dos Santos Vale ${ }^{1}$
}

Resumo: O Festival Internacional de Cinema e Vídeo Ambiental (FICA), sediado na histórica cidade de Goiás, é o maior e um dos mais importantes projetos culturais do Estado de Goiás. Resultado de um contexto sócio-histórico e político específico, o festival atende a campos e a demandas socioculturais distintas, caracterizando-se como um evento multifocal e inventivo. Destarte, o presente trabalho procura analisar o FICA, buscando visualizá-lo a partir do prisma da economia criativa. O objetivo é refletir acerca das convergências e divergências entre o arcabouço de ações do festival e alguns dos princípios dessa nova perspectiva de desenvolvimento, baseada no conhecimento, na cultura, no intangível. Para a análise dessas questões, valho-me de observação participante, realizada durante as $13^{\mathrm{a}}$ e $14^{\mathrm{a}}$ edições do FICA.

Palavras-chave: Festival Internacional de Cinema e Vídeo Ambiental (FICA), economia criativa, cultura, desenvolvimento, cidade de Goiás.

\begin{abstract}
The International Festival of Environmental Film and Video (FICA), headquartered in the historic city of Goiás, is the largest and one of the most important cultural projects of the state of Goiás, it is the result of a specific sociohistorical-political context, it attends to distinct sociocultural demands and fields, characterizing a multifocal and inventive event. Thus, this paper seeks to examine FICA, seeking to visualize it from the perspective of the creative economy. The aim is to reflect on the similarities and differences between the framework of the festival and with some of the principles of this new development perspective, based on knowledge, on culture, i.g. on the intangible. To analyze these issues, I turn to participant observation conducted during the 13 th and 14 th editions of FICA.
\end{abstract}

Keywords: International Festival of Environmental Film and Video (FICA), creative economy, culture, development, Goiás city.

\footnotetext{
${ }^{1}$ Mestrando em Antropologia Social pela Universidade Federal de Goiás - UFG, Professor de Arte - Teatro da Rede Municipal de Educação de Goiânia, integrante dos grupos de pesquisa Cultura, Memória e Desenvolvimento da UNB e Antropologia, Patrimônio, Memória e Expressões Museais.
}

Latitude, vol. 6, $\mathrm{n}^{\circ} 2$, pp.297-320, 2012

DOI: https://doi.org/10.28998/2179-5428.20120211 


\section{O Festival Internacional de Cinema e Vídeo Ambiental (FICA) e a economia criativa}

\section{Introdução}

A relação entre cultura, economia e desenvolvimento não tem sido ausente, contudo, em momentos sócio-históricos específicos ela se acentuou, revelando-se, na contemporaneidade, como núcleo de articulação das conjunturas políticogovernamentais, bem como se tornou fundamental para a compreensão dos contextos sociais em todo o globo. A noção de cultura, que, para o projeto moderno, significou atraso e selvageria, delineia-se, agora, como elemento fundamental para a integridade dos processos sociais, econômicos, estéticos, políticos etc., compreendida como um universo de possibilidades quanto à produção, à difusão e ao consumo dos bens simbólicos. Hoje, nota-se que os debates sobre cultura, economia e desenvolvimento apontam, de imediato e especialmente, para um conceito ainda em construção, mas que já demonstra revolucionar as formas de produção e consumo clássicos. Trata-se da "economia criativa".Sem, ainda hoje, haver consenso e delimitações claras, considera-se que as discussões acerca do conceito de "economia criativa" surgiram ainda no final do século XX, particularmente nos campos da indústria cultural e das comunicações. Derivado do termo creative industries² (BLYTHE, 2001), o conceito de economia criativa é mais abrangente e aponta para uma maior valorização dos processos de colaboração e para a predominância de caracteres intangíveis na geração de valores econômicos e culturais. Para Hartley (2005), a economia criativa abarca ainda o impacto dos produtos e serviços das indústrias criativas em outros setores e processos econômicos e as relações que se estabelecem entre eles. Howkins (2001), afirma que a economia criativa pode ser compreendida como um conjunto de atividades voltadas para o mercado e baseadas no potencial criativo e capital cultural dos indivíduos e nos recursos materiais disponíveis, que gera empregos, riquezas e ambientes prósperos para os negócios.

Nessa lógica, independentemente de haver definições uníssonas acerca do conceito de economia criativa, observa-se a declinação do paradigma econômico que sustentava o desenvolvimento, ou seja, a produção industrial clássica. Vê-se o surgimento de uma nova ordem econômico-produtiva, que gera novos mercados e novas formas de consumo e de relacionamento, baseando-se nas ideias, no simbólico, no capital intelectual, nos saberes tradicionais, na irreprodutibilidade da cultura, no intangível etc. A exemplo dessa nova perspectiva, que concebe a cultura como um meio catalisador do desenvolvimento, no Brasil, o Ministério da Cultura (MINC), por meio do Decreto 7743, de $1^{\text {o }}$ de junho de 2012, criou a Secretaria da Economia Criativa (SEC), com responsabilidade de "conduzir a formulação, a implementação e o monitoramento de políticas públicas para o

2 O termo "indústrias criativas" ganhou respaldo em 1997, a partir das ações multissetoriais promovidas na Inglaterra pelo primeiro-ministro Tony Blair. 
desenvolvimento local e regional, priorizando o apoio e o fomento aos profissionais e aos micro e pequenos empreendimentos criativos brasileiros" (Plano da Secretaria da Economia Criativa, 2011, p.38).

Aparentemente o que temos à frente é, então, uma nova plataforma ideológico-estratégica de desenvolvimento, que promete a expansão das capacidades individuais, a valorização das identidades e dos saberes locais, bem como garantir a autonomia cultural (política e institucionalmente) uma alternativa de superação do subdesenvolvimento brasileiro. Nessa esteira, atualmente, ressalta-se que a produção das atividades culturais brasileiras se vale fundamentalmente das leis de incentivo fiscal, sejam federais, estaduais ou municipais, e de editais de financiamento ofertados tanto pelo poder público como pela iniciativa privada. Aliado a essas perspectivas, é notável que o setor audiovisual encontre-se em destaque entre as atividades culturais da contemporaneidade, ocupando um lugar privilegiado junto ao setor econômico e assumindo um papel de grande importância nesse cenário de promoção e afirmação da diversidade cultural e de novas formas de exercício da cidadania.

Em consonância com essa dimensão e importância alcançada pelo mercado audiovisual brasileiro frente aos processos político-governamentais contemporâneos, destacadas suas especificidades e contribuições na construção de bens e expressões simbólicas, seu caráter econômico e cultural, nota-se uma significativa ampliação do circuito de festivais de cinema no país. Entre os motivos estão a ausência de interesse do empresariado de exibição comercial (os complexos multiplex) e a limitada existência de salas de exibição alternativas, que não atendem à grande demanda de produções independentes. Outro fator, sem dúvida fundamental, que corrobora para a disseminação de festivais de cinema no país é o interesse dos gestores públicos e da iniciativa privada no potencial desses eventos, considerando sua dimensão econômica (principalmente a partir de sua relação com o setor do turismo e sua contribuição para o desenvolvimento local) e política (pela visibilidade e conceituação proporcionadas a uma empresa ou gestão governamental).

Esse escopo converge com os interesses históricos de Goiás, que buscava superar certos atrasos. Na atualidade, esse esforço foi convertido em estratégias políticas voltadas para o resgate da criatividade, da tradição e da cultura local, mesclada à inovação tecnológica globalizante. Foi justamente nesse contexto que surge o Festival Internacional de Cinema Ambiental (FICA), sediado na histórica cidade de Goiás, objeto de investigação desse trabalho. O propósito é observar as consonâncias e dissonâncias do festival com alguns sentidos e pressupostos dessa nova perspectiva econômico-cultural, a economia criativa, objeto de determinadas pautas político-governamentais contemporâneas. 


\section{O Festival Internacional de Cinema e Vídeo Ambiental (FICA) e a economia criativa}

\section{Uma ideia criativa}

O FICA foi criado em 1999, como um projeto do governo do Estado de Goiás, sob encomenda do Governador recém-eleito na época, Marconi Perillo, a Luiz Felipe Gabriel, um dos coordenadores de sua campanha, que, depois, veio a ser Secretário de Comunicação. Sautchuk (2006, p.18) conta que recebeu um telefonema do publicitário Luiz Gonzaga Soares. Ele dizia que havia sido acionado por Luiz Felipe para dar conta do pedido de Marconi Perillo, disse que o Governador queria "algo para projetar Goiás nacionalmente, em termos culturais". Pouco depois, juntou-se ao time a socióloga Adnair França, esposa de Jaime Sautchuk, e, em seguida, foram angariando diversos outros parceiros. Construído e aprovado, o projeto foi executado pela Agência Goiana de Cultura Pedro Ludovico Teixeira $^{3}$ (AGEPEL), em parceria com a Agência Ambiental e a Secretaria Estadual do Meio Ambiente e Recursos Hídricos (SEMARH). Segundo informações veiculadas no site oficial do evento, o FICA foi arquitetado

Por Luiz Felipe Gabriel, Jaime Sautchuk, Adnair França e Luís Gonzaga, (...) sob a coordenação geral do cineasta João Batista de Andrade. A pouco mais de dois meses da data de sua realização (2 a 6 de junho de 1999), João Batista produziu o regulamento, estabeleceu a premiação - cada prêmio homenageia uma personalidade da cultura goiana - e criou o formato final do festival, entre outras providências (Cf. http://FICA.art.br/o-festival).

Sautchuk (2006, p.18) conta que a história da criação do FICA sintetiza-se na "junção de uma boa ideia com pessoas bem-articuladas para viabilizá-la e governantes sensíveis para encampá-la". Com a criação do FICA pretendia-se alcançar múltiplos objetivos e contribuir com diversos campos e demandas socioculturais do Estado, atraindo olhares de fora para mostrar-lhes um Goiás moderno, incluído nas possibilidades tecnológicas, mas cheio de riquezas culturais. Os objetivos eram "valorizar o cinema, discutir amplamente a questão ambiental, conquistar o título de Patrimônio da Humanidade para a Cidade de Goiás, movimentar o setor cultural como um todo, gerar riquezas (como cultura e informação), empregos e fomentar o turismo" (Cf. http://fica.art.br/o-festival). Divulga-se ainda que, devido "ao apoio e envolvimento de seus realizadores, todos

\footnotetext{
${ }^{3}$ Por meio da lei no 17.507, de 22 de dezembro de 2011, a Agência Goiana de Cultura Pedro Ludovico Teixeira (AGEPEL) passou a ser Secretaria de Estado da Cultura (Secult Goiás).
} 
esses objetivos foram alcançados em menos tempo do que se esperava" (Cf. http://fica.art.br/o-festival).

Para que possamos ter uma noção mais clara acerca das expectativas e esforços depositados nesse projeto, primeiramente é necessário compreendermos o FICA a partir da sua dinâmica político-governamental. Nesse sentido, o evento representa a consolidação do projeto ideológico apresentado pelo Partido da Social Democracia Brasileira (PSDB), nas eleições de 1998 para governo do estado de Goiás, tendo como lema de campanha a expressão "Tempo Novo". Outro ponto importante a ser considerado diz respeito ao contexto cultural em que se baseiam as análises a seguir, considerando o FICA como um estandarte da relação ambígua e conflitante entre tradição e modernidade. Assim, dentre outras importâncias, essa relação irresoluta está intimamente ligada à construção da identidade ${ }^{4}$ goiana, por se tratar de um Estado e de uma sociedade que têm buscado superar o estigma do atraso. Segundo Chaul (1995, p.93), "ao longo da Primeira República, a decadência - comumente associada à crise da mineração - ganhou conotação mais política do que econômica, e essa imagem se transmutou em atraso". Esse estigma do atraso é atribuído a toda Região Centro-Oeste, devido à distância do litoral, que dificultava o acesso de pessoas e mercadorias, conferindo poucos avanços segundo os processos de desenvolvimento baseados na modernização e industrialização. A cidade de Goiânia ${ }^{5}$ foi construída no início do século XX, fundamentalmente com o objetivo de prover a modernidade para Goiás, contudo, para inovar, pensava-se ser necessário sublimar toda tradição e cultura, seguindo à risca os preceitos racionalistas do projeto moderno. Com isso, a antiga capital da comarca ficou conhecida pelo seu conservadorismo e tradição, em contraste às dinâmicas modernas da nova capital.

No final do século XX, criou-se o FICA, mais uma vez com o intuito de inovar, de modernizar, de projetar o Estado de Goiás para o Brasil e para o mundo, mas agora por meio de uma proposta que valoriza a diversidade cultural e os

${ }^{4}$ Essa exigência de definição parece estar mais presente em sociedades que assumiram, como dilema, as especificidades do projeto de modernização. Um projeto de modernidade carrega a tensão decorrente da transformação das relações sociais advindas da expansão capitalista que, em parte, elabora um conjunto de práticas, mais ou menos homogêneas, impostas à esfera da produção, mas nem por isso opera com o fim das particularidades próprias a uma sociedade tradicional. Forma-se um campo simbólico que abriga características de um mundo tanto moderno quanto tradicional (SANDES, 2001, p.17).

${ }^{5}$ Como se saturada pelos problemas da vida moderna que invadiu a Cidade de Goiânia, esta não é capaz de ser fonte única de inspiração da identidade dos goianos. É preciso voltar ao passado para recompor a pós-modernidade em outras dimensões: o futuro só é possível se nos referenciarmos ao passado. (...) Então, goianidade que não é algo acabado e único, como todo processo de construção de ethos coletivo, é um processo aberto e fluido. Somos uma comunidade imaginada (LIMA FILHO, 2003, p. 455). 


\section{O Festival Internacional de Cinema e Vídeo Ambiental (FICA) e a economia criativa}

saberes tradicionais. Logo, a instalação de um festival internacional de cinema na cidade de Goiás sintetiza o complexo encontro (pós-modernidade) que ocorre entre a tradição e a modernidade, considerando que o cinema é uma arte/mídia/linguagem eminentemente moderna. Todavia, o FICA não é somente cinema, e nesse ponto encontra-se uma das questões chave desse trabalho, analisar sua dimensão multifocal.

Ressalta-se que o teor ambientalista do projeto e sua projeção local, nacional e mundial constroem memórias (limpas) acerca da relação entre Estado e meioambiente, em constante atualização, deixando para traz memórias trágicas, fruto de eventos que nunca serão esquecidos por algumas pessoas. O FICA representaria, então, o que Da Silva (2003, p.1) chama de "estratégias de purificação simbólica", uma forma de cura para os danos provocados pelo acidente do Césio 137 em Goiânia, que aterrorizou todo o país, em 1987. Segundo a autora, "a multiplicidade das lembranças se articula em torno de dois eixos: a memória oficial, sustentada pelas representações produzidas pelo poder institucional (...) e o saber subjugado dos sobreviventes" (DA SILVA, 2003, p.1). Outro ponto fundamental que deve ser destacado aqui, situando num contexto mais amplo a ideia do Governador Marconi Perillo, de criar o festival em 1999, é que o FICA se insere num conjunto maior, passando a fazer parte de uma rede complexa e multifacetada de serviços e de eventos econômico-culturais no Brasil. Nesse sentido, o FICA exemplifica o encontro íntimo entre economia e cultura, perspectiva que tem recebido destacado foco na pauta governamental-política contemporânea. No Brasil, os festivais foram incorporados num setor de crescente desenvolvimento, e, segundo Neolinda Vilhena:

Não é necessária uma observação aprofundada para percebermos que existe uma forte propensão das instâncias públicas em apoiar os festivais que tenham por função redinamizar o tecido econômico de certas cidades ou regiões. Nas estratégias de promoção turística os festivais se constituem com frequência na pedra angular da valorização socioeconômica do meio e justificam uma contribuição dos fundos públicos. (2011, p.3)

Analisando esse aspecto, na tabela abaixo podemos observar em números como decorreram os investimentos em algumas edições do FICA, a fim de notar o crescente respaldo financeiro dado a este festival. 
Tabela 1. Recursos Investidos Anualmente

\begin{tabular}{|c|c|}
\hline Ano & Orçamento \\
\hline 2001 & R\$ 1,2 milhão \\
\hline 2002 & R\$ 1,2 milhão \\
\hline 2003 & R\$ 1,2 milhão \\
\hline 2004 & R\$ 1,7 milhão \\
\hline 2005 & R\$ 2,5 milhões \\
\hline 2006 & $\mathrm{R} \$ 2,6$ milhões \\
\hline 2007 & $\mathrm{R} \$ 2,4$ milhões \\
\hline 2008 & $\mathrm{R} \$ 2,2$ milhões \\
\hline 2012 & R\$ 4 milhões \\
\hline
\end{tabular}

Site oficial do FICA <http://FICA.art.br $>$

Por outro lado, existem outras contribuições e possibilidades que despertam o interesse político, público e privado em criar, financiar e apoiar etc. um festival, , mais especificamente um festival de cinema, como o FICA. Alguns desses atores ${ }^{6}$ são, entre outras as empresas de infraestrutura, a Labocine, a Kodak, a Link Digital, os Estúdios Mega, a Megacolor e a Casablanca. Também órgãos federais voltados ao audiovisual, como o Centro Técnico Audiovisual (CTAV) - vinculado à SAV, a ANCINE, o Ministério da Indústria e Comércio Exterior e o Banco Nacional de Desenvolvimento e Econômico Social (BNDES). Ainda o Banco do Brasil, a Petrobrás, a Eletrobrás, o Banco do Nordeste, a Caixa Econômica Federal, a Infraero, a Empresa Brasileira de Correios e Telégrafos e a Companhia Hidroelétrica do São Francisco (CHESF) (empresas estatais e/ou de capitais misto), a Rede Brasil e o Canal Brasil (empresas privadas). Ademais, esse interesse se fundamenta uma vez constatado que:

A importância dos festivais vai além da simples questão financeira. Sabe-se que, onde há festivais, há também um intercâmbio cultural pulsante, geração de empregos (cerca de seis mil por ano) e estímulo a negócios culturais. Isso sem falar na formação de platéias, peça-chave para o crescimento cinematográfico nacional. Por isso, na primeira década do século 21 , o negócio dos festivais cresceu $20 \%$ ao ano. (BALLERINI, 2012, p.189)

Nessa direção, o expressivo crescimento do circuito de festivais de cinema no Brasil, considerando que, em 1999, foram realizados 38 eventos, que subiram para 132 festivais, em 2006, bem como apontam os dados da pesquisa realizada pelo Fórum Nacional dos Organizadores de Eventos Audiovisuais, publicada em 2007. Tal circuito movimenta em média 20 milhões por ano, a exemplo do FICA, há uma variante nos mecanismos de financiamento, ou seja, os recursos financeiros

${ }^{6}$ Fórum Nacional dos Organizadores de Eventos Audiovisuais. Diagnóstico setorial / 2007. 


\section{O Festival Internacional de Cinema e Vídeo Ambiental (FICA) e a economia criativa}

advêm tanto de patrocínios cedidos por empresas e instituições privadas, como por meio de leis de incentivo e/ou por financiamento público direto. Segundo apresenta Zita Carvalhosa, no Guia Brasileiro de Festivais de Cinema e Vídeo (1999), os festivais possibilitam a exibição anual de mais de 20 mil obras entre filmes e vídeos, contemplando cerca de 2,5 milhões de espectadores, causando significativo impacto em outros setores, como o turismo, acabando por dinamizar a economia brasileira.

É claro que seria ingenuidade pensar que há uma distribuição igualitária desses festivais pelas regiões brasileiras, logo, é na Região Sudeste que se concentra a maior parte desses eventos. O Sudeste lidera também outras estatísticas que abordam a área da cultura, inscrevendo e aprovando mais projetos em leis de incentivo à cultura, seleções públicas e outros editais de âmbito nacional. Contudo, apesar dessa concentração, "outras regiões do país apresentam festivais consolidados no circuito, com anos (e até décadas) de realização contínua e com enorme capacidade para alavancar negócios e parcerias com base no seu potencial artístico-cultural" (LEAL E MATTOS, 2009, p.4 - grifos no original). Destarte, observando as estatísticas que abarcam os resultados de cunho econômico apresentados no Diagnóstico Setorial 2007 / Indicadores 2006 dos Festivais Audiovisuais, é possível verificar que o circuito de festivais de cinema apresenta-se como fundamental para as dinâmicas da economia criativa, dada sua expressiva contribuição para o desenvolvimento social, cultural e, sobretudo, econômico, de amplitude local e nacional. Nessa lógica, podemos destacar a geração de empregos diretos e indiretos, de renda e de impostos; a criação de bens culturais e a dinamização da economia de serviços; a formação de parcerias e a atração de investimentos.

\section{A dinâmica multifocal do FICA}

Nos anos de 2011 e 2012, durante as $13^{\mathrm{a}}$ e $14^{\mathrm{a}}$ edições do FICA, tive a oportunidade de visitar a histórica cidade de Goiás, com o intuito de realizar uma pesquisa de campo. Nesse ínterim, transitei pelos espaços da cidade observando as diversas ações promovidas pelo Governo do Estado para o festival. Pude notar, então, que há uma multiplicidade e diversidade de ações resultantes não somente da iniciativa pública, como também de caráter independente, grande parte empreendida pela população local. Para melhor compreendermos esse arranjo, dividi as iniciativas em dois grupos. O primeiro elenca ações que compõem oficialmente o FICA. Nesse grupo, reúnem-se os pilares do festival, composto por inúmeras ações, as quais muitas vezes, acontecem sincronicamente, ou seja, diante de um vasto leque de possibilidades o público deve decidir entre ir ao debate de um filme, participação em um minicurso de cinema ou fórum ambiental, assistir a uma apresentação de teatro ou dança etc. Todavia, essa 
multiplicidade de elementos em oferta faz com que o público também se diversifique.

A Mostra Competitiva é o chamariz para os olhares estrangeiros, locais e de outros polos cinematográficos nacionais, e representa um elo cultural entre o regional e o global. Os prêmios dessa mostra somam 200 mil reais, sendo que 80 mil desse total dividem-se em dois prêmios de 40 mil direcionados às produções goianas. As obras dessa mostra dedicam-se especificamente à temática do meio ambiente, sendo contemplados filmes, vídeos e séries de TV, exibidos no Cine Teatro São Joaquim 7 . A participação e a conquista de prêmios no FICA não se restringe a receber um montante em dinheiro, refere-se, ainda, ao acúmulo de capital simbólico. Em várias edições do festival, os filmes vencedores foram exibidos posteriormente em TV aberta, por meio do programa DocTv Goyaz, da Televisão Brasil Central (TBC). Também passam a fazer parte do "FICA Itinerante", ação pós-festival que exibe publicamente esse conjunto de filmes em diversos municípios no interior do Estado de Goiás e em diversos estados brasileiros.

A Mostra ABD-GO Cine Goiás que acontece no Cinemão ${ }^{8}$ é composta por produções audiovisuais goianas de qualquer temática, gênero e duração. Sem dúvida, a Mostra ABD-GO é um dos mais importantes espaços para o cinema goiano, um ambiente propício para se conhecer as produções locais, oportunizando o surgimento de novos talentos, além de distribuir prêmios em dinheiro. Para outros públicos, como as crianças, por exemplo, há a mostra infantil "FICA animado", que ocorre também no Cinemão, e, em 2012, completou sua quarta edição. Para quem produz nessa linha, também se acrescenta uma oportunidade para expor seu trabalho e conhecer os trabalhos de outros cineastas. De forma geral, ter o filme selecionado e exibido no FICA significa abrir um leque de possibilidades, de caminhos para o filme e, fundamentalmente para seus realizadores.

É significativa a contribuição do festival na formação e capacitação de pessoal para a atuação no setor audiovisual, em Goiás, fundamentalmente no campo cinematográfico, considerando que somente em 2006, surgiu o primeiro curso superior em audiovisual do Estado de Goiás, oferecido pela Universidade

\footnotetext{
${ }_{7}^{7}$ Trata-se do mais antigo teatro do estado, construído em meados do século XIX, foi palco de inúmeros espetáculos produzidos no Rio de Janeiro e em São Paulo. Porém, ganhou poucas atenções da administração pública desde a transferência da capital para a recém construída cidade de Goiânia. Em 1992 foi restaurado e a partir de 1999, adaptado para atender ao FICA, passou a exibir os filmes da mostra competitiva do festival, tornando-se Cine Teatro São Joaquim.

${ }^{8}$ Sala de cinema improvisada, montada na quadra de esportes do Colégio Estadual Prof. Alcide Jubé, com capacidade para oitocentas pessoas, localizada no centro histórico da cidade de Goiás.
}

Latitude, vol. 6, n², pp.297-320, 2012 


\section{O Festival Internacional de Cinema e Vídeo Ambiental (FICA) e a economia criativa}

Estadual de Goiás (UEG). Até a criação do FICA, somente havia produção de conhecimento nessa área por meio dos cursos de Rádio e TV (criado em 1981 e extinto em 2004) e Jornalismo (ofertado desde 1968), oferecidos pela Universidade Federal de Goiás (UFG). Contudo, os conteúdos e métodos cinematográficos que constam nas grades curriculares desses cursos são restritos, não suprindo inúmeras carências técnicas e profissionais. Daí, a importância das diversas oficinas, palestras, minicursos e workshops oferecidos ao longo do tempo pelo FICA, desde sua criação.

Em sua trajetória, o FICA reuniu pessoas de relevo do cinema nacional e mundial, seja para coordenar o festival, para compor os quadros do júri oficial, para ministrar cursos, participar de mesas redondas, fóruns, debates etc. Já passaram pelo festival os cineastas João Batista de Andrade, Nelson Pereira dos Santos, Gustavo Dahl, Tatá Amaral; o diretor de fotografia Dib Lutfi; os documentaristas Wladimir Carvalho, Sílvio Tendler, João Moreira Salles, Silvio DaRin; os pesquisadores e professores Ismail Xavier, Jean Claude Bernardet, Rubens Machado, Jorge Bodeansky, Fernão Ramos, Maria Mourão, Jacques Aumont; estrangeiros como Christopher Hanson (representante do festival de Cinema de Washington - EUA), Neil Curry (cineasta sul-africano e diretor do Festival Ambiental da África do Sul); entre outros nomes de vulto.

Nessa esteira, a temática do meio ambiente também é atendida pelo FICA. Em 2012 foi promovido pela Secretaria do Meio Ambiente e Recursos Hídricos de Goiás (Semarh) um Fórum Ambiental, distribuído em três eixos: "Rio + 20: Resultados e Perspectivas - Encontro com Celso Schenkel e Fernando Gabeira" (na ocasião, foram lançados os Comitês das Bacias dos Rios Vermelho e do Rio dos Bois), "O papel da TV na conservação ambiental - Encontro com Paula Saldanha" e "O papel da música na conservação ambiental - Encontro com Paulinho Pedra Azul e Marcelo Barra". Também ocorreram oficinas, como "Sustentabilidade em eventos culturais", "Uso do bambu na construção civil", "Reaproveitamento de Materiais Para Decoração de Ambientes", "Produção de produtos de higiene e limpeza com fragrâncias do cerrado" e "Blocos Musicais Sustentáveis". Grande parte dessas ações envolve pessoas que desenvolveram ou trabalham com um saber específico, nesse caso, a diversidade e especificidade culturais extrapolam os limites de um mercado industrial saturado, aplicando-se a múltiplos e novos contextos, apontando maneiras de se gerar empregos, renda e valorizar a cultura.

Uma iniciativa singular e fundamental foi a criação do Empório SEBRAE FICA de Cinema e Vídeo, que surgiu de uma parceria entre a AGEPEL e o SebraeGo, em 2004, e foi instalado nas dependências do Colégio Estadual Alcide Jubé, no centro da cidade. O objetivo desse projeto foi promover iniciativas que possam capacitar e aproximar os profissionais do setor audiovisual em Goiás, oportunizando também a realização de negócios e parcerias. O Empório já promoveu ações voltadas ao meio ambiente e sustentabilidade, bem como 
contempla outras frentes, como o artesanato, a moda, o design etc.Todos os anos, o Empório oferece uma extensa programação, com palestras, exposições, debates, encontros, rodas de negócios, oficinas, minicursos, lançamentos de obras literárias e cinematográFICAs etc. Mais do que isso, segundo o atual diretor-técnico do Sebrae em Goiás, Wanderson Portugal, o Empório aproxima empreendedores culturais, fundamentando-se na concepção de economia criativa, e realiza ações antes e após o festival, capacitando até mesmo os comerciantes locais (CARDOSO, 2012).

Em 2011, durante o 13ํㅡㄹ FICA, houve uma ação chamada "Teia Goiás" com o tema Cidadania e Diversidade - Novos Rumos do Programa Cultura Viva no Centro Oeste, reunindo representantes dos Pontos de Cultura de Goiás, gestores da AGEPEL e do MINC. Durante o encontro, os pontos de cultura presentes tiveram a oportunidade de realizar apresentações artísticas, expondo os saberes diversos e as práticas culturais. Existe, ainda, uma ação intitulada "FICA na comunidade", que promove algumas atividades na periferia e área rural da cidade de Goiás, durante o festival, sejam mostras de filmes, oficinas ou intervenções artísticas, como, por exemplo, em 2012, quando artistas plásticos desenvolveram um trabalho na fachada de algumas casas, na periferia. A ação contou com visitas à comunidade e diálogo com os moradores, para que decidissem quais se interessariam em ter suas casas inseridas na ação.

As apresentações musicais são importantes atrações no arranjo criativo do festival, sendo responsáveis por grande parte do público presente, principalmente em se tratando dos artistas que encerram o evento, sempre uma personalidade de destaque no cenário. No ano de 2012, por exemplo, 35 mil pessoas assistiram a apresentação de Caetano Veloso. Os shows de encerramento levam à cidade de Goiás, sempre grandes nomes da música brasileira. Já passaram pelo palco do FICA: Elba Ramalho, Zé Ramalho e Geraldo Azevedo com o "Grande Encontro", Milton Nascimento, Paralamas do Sucesso, Titãs, Ed Mota, Cidade Negra, Luiz Melodia, Gilberto Gil, Rita Lee, Maria Rita, Nando Reis, Orquestra Imperial, Caetano Veloso, entre outros. Em 2011, o festival trouxe, pela primeira vez, uma atração musical internacional, o francês Mano Chao. Para os músicos goianos, é uma grande oportunidade de se apresentar com público garantido, estrutura profissional, mídia etc. Entretanto, uma novidade interessante é que, em 2011, a AGEPEL "aumentou de $\mathrm{R} \$ 3.500$ para $\mathrm{R} \$ 6.000$ os cachês pagos aos músicos regionais para a $13^{a}$ edição do Festival Internacional de Cinema e Vídeo Ambiental". O que tornou ainda mais interessante ser selecionado para tocar no FICA, estimulando a produção musical local.

Para os shows do $14^{\circ}$ FICA, foram registradas outras inovações, dessa vez quanto à ocupação dos espaços e a diversidade das apresentações artísticoculturais (incluíram-se nessa edição as apresentações dos pontos de cultura). Segundo o site oficial do evento, os artistas goianos "lotaram os palcos Beira Rio e 


\section{O Festival Internacional de Cinema e Vídeo Ambiental (FICA) e a economia criativa}

Mercado. (...) Além disso, nesta edição dois novos locais - as Praças do Coreto e do Chafariz - também serviram de palco (...)". Acompanhando e completando os sentidos desse evento multicultural, destaca-se o empreendimento do turismo. O Ministério do Turismo estabeleceu alguns seguimentos turísticos, apontando-os como fundamentais nos processos de desenvolvimento no país. O turismo cultural está entre os segmentos em destaque, e o FICA pode ser considerado um exemploação desse segmento.

O desenvolvimento desse tipo de turismo deve ocorrer pela valorização e promoção das culturas locais e regionais, preservação do patrimônio histórico e cultural e geração de oportunidades de negócios no setor, respeitados os valores, símbolos e signifICAdos dos bens materiais e imateriais da cultura para as comunidades. (p.11)

Ora, a escolha da cidade de Goiás, antiga capital da comarca, para sediar o festival, não foi por acaso, destacando-se os interesses estéticos e identitários, considerando a importância sócio-cultural e política da cidade. A criação do FICA gerou um significativo impacto simbólico no governo de Marconi Perillo, passando a expressar uma identidade da sua gestão, levando em conta também a visibilidade em âmbito nacional e internacional, ocasionada pela amplitude e repercussão do evento. A cada edição do FICA, mais de 100 mil pessoas transitam pelos becos e ladeiras da cidade, contemplando suas paisagens natural, cultural e social. Logo, não há como não fitar os olhos, por algum instante, num detalhe arquitetônico colonial das inúmeras construções do século XVIII, que estão preservadas, como, por exemplo, a Igreja da Boa Morte, que contém elementos legítimos do barroco, em sua fachada.

Nessa mesma igreja foi instalado o Museu de Arte Sacra, que abriga a maior parte das obras de Veiga Valle, escultor local do século XIX. Há também os museus Casa de Cora Coralina, da Bandeira, do Palácio Conde dos Arcos e o Espaço Cultural Goiandira Ayres do Couto, entre outras igrejas e lugares muito visitados pelos turistas. Destaca-se que, em 2001, a cidade de Goiás recebeu da UNESCO o título de Patrimônio Histórico Mundial, concessão que legitima a história da conquista do oeste brasileiro e favorece significativamente o turismo históricoarquitetônico.

Segundo dados do $6^{\text {o }}$ Batalhão da Polícia Militar, em 2012 o público do festival chegou a 140 mil pessoas. Parte dessa multidão somente chega à cidade de Goiás no final de semana, especificamente para ver as atrações musicais de encerramento. Contudo, a soma de todas as pessoas envolvidas na produção do evento, considerando ainda os artistas e intelectuais convidados, já ocupa os principais hotéis e movimenta os principais restaurantes da cidade. O aumento do fluxo de pessoas, impactando também na demanda pelos serviços e produtos da cidade, observa-se outro conjunto de ações. Esse grupo representa todos aqueles que, de forma direta, se beneficiam do movimento turístico promovido pelo 
festival, todos os anos. É notável que a economia da cidade seja inteiramente beneficiada com o evento, contando com uma arrecadação de cerca de $\mathrm{R} \$ 1,5$ milhão (REVISTA DO FICA, 2011). Para a chegada do FICA, muitos comerciantes, donos de pousadas e hotéis, realizam benfeitorias em seus estabelecimentos, reformam, pintam, modificam os cardápios e aumentam as acomodações. As doceiras e os artesãos intensificam seus trabalhos, aumentando suas produções, esperando as vendas em abundância. É possível alugar casas para temporada, todavia, diversos moradores fracionam essa possibilidade e disponibilizam quartos, garagem e quintais de suas casas para aluguel, passando a conviver com aquele "hóspede" durante os dias e noites do evento. Outros, que não dispõem de uma casa ampla, com vários quartos, quintal ou garagem, fazem arranjos mais radicais ainda. Em 2012, um senhor transferiu sua mulher e filhos para um barraco que estavam terminando de construir e me alugou o barraco em que moravam por dois dias, me cobrando $\mathrm{R} \$ 400$ por esse serviço alternativo, mas rotineiro.

Acompanhando o ritmo da programação do festival, surgem muitos ambulantes, a maioria vendendo cerveja, refrigerante e água. Onde quer que a multidão esteja lá estarão eles. Como a programação artístico-cultural é volumosa, com destaque para as apresentações musicais a céu aberto, existe uma grande demanda para esse serviço. Aproveitando a grande circulação de pessoas, além das lojinhas de artesanato que ficam no centro da cidade, existem artesãos que expõem suas peças em lugares mais periféricos, contudo estratégicos, como na entrada da cidade. Observa-se ainda, que uma pequena feira é montada próximo à praça do coreto, oferecendo diversos produtos, como pulseirinhas e colares, tatuagens de henna, roupas, sandálias etc. A feira agrega, além disso, os chamados hippies e, à noite, as barraquinhas de bebidas, de churrasquinho, de cachorro-quente, de crepe, de pastel etc., que também aparecem. Durante o FICA, é comum acontecer apresentações artísticas espontâneas, ou seja, não previstas na programação oficial. Muitos artistas circenses, atores e poetas da cidade ou de fora, surpreendem as pessoas com números de malabarismo, esquetes teatrais, poesias recitadas etc. Enquanto alguns querem apenas divulgar seu trabalho, outros esperam uma contribuição (dinheiro), também espontânea, do público. Alguns bares da cidade também acolhem esse tipo de iniciativa, abrindo espaço para músicos e bandas, em geral, amadores.

\section{Distanciamentos e aproximações}

Após esse percurso, no qual foram identificadas as principais ações formais e informais que compõe esse arranjo multifocal, que é o FICA, é possível observar quais os pontos consonantes com a perspectiva de desenvolvimento proposta e acionada pela economia criativa, buscando contemplar alguns sentidos e 


\section{O Festival Internacional de Cinema e Vídeo Ambiental (FICA) e a economia criativa}

pressupostos fundamentais, que para fins analíticos serão classificados em três frentes: (1) economia e sociedade; (2) sustentabilidade e (3) gestão compartilhada.

\section{1 - Economia e Sociedade}

Inicialmente, é necessário ressaltar que, em tempos globalizados, o FICA apresenta um diferencial necessário em relação ao conjunto nacional de festivais cinematográficos, sobretudo por sua multifocalidade, ou seja, por arrebatar diversos setores e demandas socioculturais de uma só vez, considerando sua extensa e diversificada programação artístico-cultural e de ações formativas. O FICA oferece ainda "a maior premiação da América Latina no gênero: R\$ 240 mil em prêmios" (Cf. www.fica.art.br/o-festival). Segundo Gilvane Felipe, Secretário de Cultura do Estado, "O FICA é o espaço da experimentação, de novos rumos, palco da disponibilidade da cultura e da ousadia. E a cidade de Goiás é a casa perfeita para receber esse caldeirão criativo" (HELI, 2012). Como observamos, a cidade de Goiás reserva grandes atrativos para quem a visita, entre eles sua beleza estético-arquitetônica, sua importância histórica, seus patrimônios culturais, tradições, suas belas paisagens, frutos e flores do cerrado. Todo esse arcabouço é acionado pelo FICA, que gera mercado de consumo. Contudo, vale ressaltar que ao término do festival esse mercado se dissolve, o que pode ocasionar uma dependência do produtor ao calendário do evento, e até mesmo a interrupção da atividade. Prova disso são as doceiras da cidade de Goiás, que chegam a faturar cinco vezes mais durante o festival do que ganhariam em um mês comum de vendas. Porém, essas mulheres, importantes figuras da cultura local, dizem enfrentar muitas dificuldades para continuar com a atividade, principalmente as baixas vendas fora de temporada (REVISTA DO FICA, 2011).

Buscando alternativas, a partir de um diálogo com a empresária goianiense Adriana Lira e com o chef vilaboense Aloísio Godinho, as doceiras tiveram uma iniciativa com a intenção de não deixar esses saberes se extinguirem. Trata-se da criação da Associação das Doceiras de Goiás, que, em 2011, reivindicou e conseguiu, junto à organização do FICA, um estand para expor os doces (REVISTA DO FICA, 2011). Quanto à geração de empregos, o festival tem possibilitado aos moradores da cidade oportunidades de trabalho temporário, demandando pessoas para as mais diversas áreas e funções. Em 2011, cerca de 280 pessoas trabalharam no evento. Segundo o coordenador operacional, Rodrigo Santana, "o planejamento é feito com participação de vários segmentos da cidade. Desde os movimentos culturais até a universidade, a associação de hotéis, pousadas e restaurantes, a prefeitura da cidade e outros" (REVISTA DO FICA, 2011, p. 34). Desse modo, o FICA contribui bastante para a economia local, mesmo levando em consideração sua sazonalidade, ou seja, grande parte dos valores monetários que são gerados durante o evento é investida processualmente, gerando um circuito econômico que 
se estende após o festival. Nesse sentido, todos os que foram beneficiados financeiramente durante o FICA (comerciantes, empresários, artesãos, doceiras, ambulantes, moradores locais etc.), passam, em seguida, a fazer circular esse dinheiro entre si e os demais mercados de bens e serviços locais.

No que se refere à escolha e articulação dos espaços operacionais e aqueles que abrigam os eventos, o festival se destaca ao ocupar alguns prédios históricos e escolas da cidade, evitando a construção de novos espaços e, ainda, valorizando e divulgando a cultura local. Em 2012, o Palácio Conde dos Arcos foi o lugar escolhido para a abertura oficial do $14^{\circ}$ FICA. No Cine Teatro São Joaquim, é exibido o conjunto de filmes da Mostra Competitiva, os vencedores dessa mostra e da Mostra ABD-GO Cine Goiás. No Colégio Estadual Alcide Jubé são instalados o Cinemão e o Empório Sebrae. Esse ano, o antigo Liceu de Goiás recebeu os encontros dos pontos de cultura. O credenciamento dos participantes, a sala de imprensa, exposições etc., são realizados no Quartel do XX9. Entretanto, mesmo apresentando essas soluções, o FICA ainda tem que arcar com a montagem de uma infraestrutura muito grande, todos os anos.

O conhecimento, fonte renovável, fundamental para os produtos e serviços criativos, é um dos focos principais do festival. Com uma programação extensa de oficinas, workshops, minicursos, fóruns, palestras, debates etc., o objetivo é conseguir alcançar e contribuir com diversos setores, considerando que o cinema (audiovisual) e o meio-ambiente são fundamentais, por meio dos quais se conectam os outros. Nesse sentido, o FICA pode ser visto como um agente dinamizador, impactando diversas atividades econômicas, qualificando o capital humano, fornecendo ambientes propícios para a formação de redes e parcerias. Em 2011, na abertura do $13^{\text {o }}$ FICA, em seu discurso, o Governador Marconi Perillo enfatizou, entre agradecimentos e palavras simpáticas, que a "identificação do povo era o tema do festival". Após a fala do governador, entraram em cena Almir Pessoa e a Orquestra de Violeiros de Goiás, tocando canções populares e catira, animando a plateia.

\section{2 - Sustentabilidade}

Uma das principais prerrogativas da economia criativa é poder contar com fontes inesgotáveis, renováveis e em abundância, como a cultura, o simbólico e o intangível. Logo, o caminho a ser seguido é diferente ao da economia tradicional, que se sustenta a partir dos recursos tangíveis, físicos e findáveis. Portanto, os

${ }^{9}$ Mais antigo prédio público estadual, construído em 1747. Possui características das construções militares coloniais, destacando-se ainda sua importância para os movimentos político-sociais do estado. Em 1982 foi restaurado e passou a sediar a regional do Tiro de Guerra, a Secretaria Municipal de Cultura, além de abrigar o arquivo da prefeitura.

Latitude, vol. 6, n², pp.297-320, 2012 


\section{O Festival Internacional de Cinema e Vídeo Ambiental (FICA) e a economia criativa}

processos da economia criativa têm como foco o desenvolvimento sustentável e não apenas o desenvolvimento econômico. Nesse ponto, o FICA encontra um dos seus maiores dilemas: será que os impactos causados são simultaneamente positivos, tanto para as esferas econômica, social e cultural, como para o meioambiente? Bem, se um grande número de turistas propicia um grande ganho econômico, ao mesmo tempo gera um enorme volume de lixo para a cidade, considerando, ainda, as toneladas de equipamentos e de material para infraestruturas, o fluxo de carros e de pessoas. Apesar de mais de $90 \%$ do lixo gerado ser de materiais recicláveis, nos anos anteriores, como em 2010, por exemplo, menos de $20 \%$ dos resíduos produzidos durante o evento tiveram como destino a reciclagem (REVISTA DO FICA, 2011). Na tentativa de sanar essa deficiência, em 2011 foi criado o programa FICA Limpo, especificamente voltado para a limpeza da cidade nos dias do festival. O projeto propõe a sistematização da coleta de resíduos, tendo inclusive instalado alguns pontos para entrega voluntária de lixo seco.

Outras pautas bastante debatidas referem-se ao comprometimento com a cidade de Goiás, à ocupação e à preservação do centro histórico, à valorização do cerrado e à conservação do título de Patrimônio Histórico da Humanidade. Em decorrência dessas preocupações, foram formuladas algumas modificações na estrutura do festival. Por exemplo, a partir de 2010, as apresentações musicais, que antes aconteciam no centro histórico, passaram ser realizadas no Largo do Matadouro (Praça de Eventos Beira-Rio).

O desenvolvimento e a prática da responsabilidade ambiental, não somente por parte dos turistas, mas também por parte dos moradores locais, é essencial quando se trata de sustentabilidade, pois reflete na criação de novas posturas e atitudes, sentimento de preservação, o que enriquece o valor cultural e histórico da cidade, agregando valores específicos à marca do festival e à articulação dos seus significados. O FICA tem procurado se alinhar a essa perspectiva, um exemplo é a mostra infantil FICA Animado, que oferece para alunos das escolas públicas locais a oportunidade de assistirem a filmes de curta-metragem que discutem a temática ambiental, durante duas manhãs. Segundo dados do festival, em 2012, a primeira sessão da mostra reuniu mais de 800 alunos no Cinemão. O festival promove ainda um leque de ações de caráter educativo e reflexivo, como oficinas, fóruns, minicursos, entre outros, sendo que algumas dessas iniciativas têm como foco os moradores da cidade, a comunidade rural e as escolas. Porém, na maioria das vezes não há uma continuidade dessas ações, o que compromete o alcance de resultados mais profícuos. 


\section{3 - Gestão Compartilhada}

Um dos pressupostos da economia criativa é o estabelecimento da gestão compartilhada, ou seja, requer transversalidade entre as pastas do governo, promovendo políticas multissetoriais. No entanto, não se trata de simplesmente fragmentar o planejamento, o investimento, a execução de políticas, mas sim de integrar diferentes pastas a partir de uma visão sistêmica de desenvolvimento, para que, de fato, ocorram gestões compartilhadas. Segundo o Fonseca (2011, p.76)

É impossível falar de economia criativa como estratégia de desenvolvimento sem incorporar, além das pastas de cultura e de desenvolvimento, a política educacional [...]; sem recorrer à política de ciência e tecnologia (partindo do pressuposto de que exclusão digital também é exclusão cultural) e sem dialogar com a política de relações exteriores (a história nos mostra que toda potência mundial política também foi uma potência econômica e cultural.

Em suas cinco primeiras edições, a realização do FICA envolvia duas pastas do governo, a AGEPEL e a Agência Ambiental, mas, aparentemente, essa não foi uma parceria espontânea e muito colaborativa, pois o que houve foi uma alternância entre as pastas na execução do evento. A partir de 2004, o festival passou a ser de responsabilidade apenas da AGEPEL, que ficou com a missão de elaborar o projeto e executá-lo. Por outro lado, tornou-se forçoso a necessidade de se estabelecer parcerias, condição basilar para um evento com tamanha diversificação, abrangência e porte como o FICA. O festival já contou com o apoio da Prefeitura da Cidade de Goiás, da Secretaria de Educação do Estado de Goiás (SEDUC), da Secretaria do Meio Ambiente e Recursos Hídricos do Estado de Goiás (SEMARH), da Agência Goiana de Turismo (AGETUR), da Agência Goiana de Comunicação (AGECON), da Secretaria da Fazenda (SEFAZ), entre outras pastas do governo.Também já foram parceiros: a Universidade Federal de Goiás (UFG); a Universidade Estadual de Goiás (UEG); a Pontifícia Universidade Católica de Goiás (PUC-Goiás); o Instituto do Patrimônio Histórico e Artístico Nacional - Goiás (IPHAN-GO); o Serviço Nacional de Aprendizagem Comercial - Goiás (SENACGO); o Serviço Brasileiro de Apoio às Mico e Pequenas Empresas - Goiás (SEBRAE-GO); a Associação Brasileira de Documentaristas - Sessão Goiás (ABDGO); a TeleImage; a Fujifim; a Natura; o Banco do Brasil; a Vivo; a TV Cultura; a Rádio CBN; a Organização das Nações Unidas para a Educação, a Ciência e a Cultura (UNESCO), entre vários outros. 


\section{O Festival Internacional de Cinema e Vídeo Ambiental (FICA) e a economia criativa}

A princípio, todo esse conjunto de agentes nos leva a pressupor a existência de uma visão sistêmica, que conecte cada parte com às demais, subsidiando os processos de comunicação e de colaboração da rede estabelecida. Mas essa configuração do festival (resultado de um processo sócio-histórico) evidencia, ainda, apenas um potencial à transversalidade, elemento nuclear da economia criativa. O ideal proposto por esse novo prospecto do desenvolvimento aponta para a necessidade de uma gestão compartilhada, que, de fato, extrapole os vieses governamentais e alcance também "o setor privado (que aporta recursos, expertise e dinamismo - afinal, economia não se faz por decreto) e sociedade civil (que zela pela continuidade e pela transparência dos processos)" (FONSECA, p.76).

\section{O FICA e o crescimento do audiovisual}

O cinema brasileiro da década de 1990 foi marcado por um período de inúmeras carências relativas à relação entre o Estado e o setor cinematográfico. Momento caracterizado pela inexistência de um órgão específico para defender, incentivar, promover, regular e fiscalizar a atividade cinematográfica nacional, bem como por insuficiências dos mecanismos das leis de incentivo indireto, que somente contemplavam a produção, não atendendo às necessárias interconexões com os demais elos da cadeia produtiva. Logo, é no limiar desse contexto que surge o FICA, momento em que eclodiam transições e transformações do setor audiovisual. Destarte, a partir de então, é possível falar do início de uma nova fase da atividade cinematográfica no Brasil, resultado de incessantes reivindicações da comunidade cinematográfica brasileira, relativas à necessidade de uma reestruturação do mercado e de um redirecionamento das políticas públicas para o setor, sobretudo encampadas pelo III Congresso Brasileiro de Cinema (CBC), realizado em junho de 2000, na cidade de Porto Alegre. Com efeito, nos últimos dez anos o mercado audiovisual brasileiro cresceu substancialmente, situando-se num crescente fluxo de aproximações entre a cultura e a economia. Podemos apontar alguns fatores que foram fundamentais para esse avanço, como a reestruturação da Secretaria do Audiovisual (SAV), a criação da Agência Nacional do Cinema (ANCINE), do Conselho Superior de Cinema (CSC), da Contribuição para o Desenvolvimento da Indústria Cinematográfica Nacional (CONDECINE), do Fundo Setorial do Audiovisual (FSA) e, mais recentemente, a criação da Lei 12.485/11.

Desde a sua criação, a ANCINE passou a cumprir seu papel em regulamentar e instaurar mecanismos para fiscalizar e controlar o mercado, procurando ainda uniformizar os processos para a efetivação de produções audiovisuais, atuando conjuntamente com a SAV - responsável por assistir, formatar e executar políticas para o setor em âmbito cultural - e com o CSC incumbido de elaborar a política nacional do cinema, em âmbito industrial. Essa 
articulação resultou num aquecimento da produção cinematográfica nacional. Segundo dados da ANCINE, mais de $\mathrm{R} \$ 120$ milhões foram arrecadados anualmente, possibilitando um gradual crescimento do mercado que, de pouco mais de 30 filmes lançados em 2000, chegou a mais de 70, em 2007, bem como demonstrado no quadro abaixo.

Tabela 2. Evolução do Mercado Cinematográfico Brasileiro: 2000 a 2007

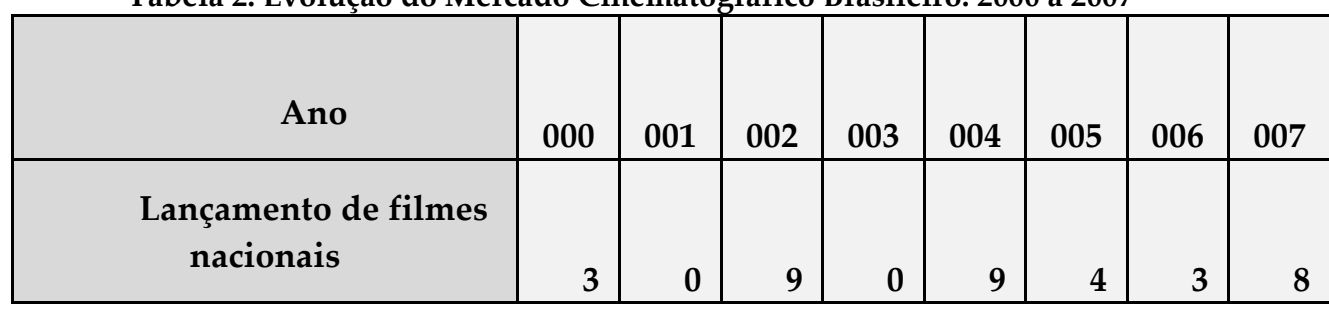

Fonte: ANCINE, 2013

Mesmo que tenha acrescido, todavia, o setor por constituir um importante órgão central, a ANCINE não cobriu a lacuna referente à sistemática tarefa do Estado em implementar políticas que possibilitassem a real entrada da produção nacional no mercado, não encerrando a distância institucional entre o cinema e a televisão. Seguia também, a dependência do setor do cinema em relação ao Estado, uma vez que o principal viés de financiamento continuou a ser as leis de incentivo fiscal, que já exibiam fragilidades e ineficiências anteriormente à criação do órgão, como, por exemplo, contemplar estritamente a produção, deixando de atender aos demais elos da cadeia audiovisual. Destarte, esse cenário começa a mudar, não pelo desempenho do Estado, mas sim pela atuação da iniciativa privada (televisão), que passou a figurar como agente político. Nessa esteira, destacam-se especificamente as demandas geradas pelas Organizações Globo, sobretudo por meio da produtora Globo Filmes. Segundo Bahia "A participação da TV Globo no cinema nacional, através da Globo Filmes, imprime novas marcas no campo audiovisual nacional, gerando transformações no mercado e na linguagem audiovisual brasileira".

Seguindo nessa direção, acompanhando os recentes processos de transformação do cenário político-cultural brasileiro, considerando os esforços empreendidos pelo Estado para se adequar às perspectivas da economia criativa, podemos citar a criação Fundo Setorial do Audiovisual (FSA) e a promulgação da Lei 12.485/11 como medidas fundamentais para o avanço técnico e qualitativo do setor cinematográfico e sua efetiva entrada no mercado audiovisual, com vistas à sustentabilidade. Com a criação do FSA, em 2008, torna-se possível falar de um desempenho comercial do setor do cinema, que se integra à seara das obras audiovisuais que circulam em diversas plataformas midiáticas. Destarte, o que ocorre é uma transição, marcada por uma mudança do modelo de financiamento 


\section{O Festival Internacional de Cinema e Vídeo Ambiental (FICA) e a economia criativa}

da cadeia produtiva do audiovisual brasileiro, refletindo uma potencial dilatação do mercado e um crescimento dos investimentos por parte da iniciativa privada. Pode-se considerar, em hipótese, ainda, que a atuação do FSA é estrategicamente coerente com uma perspectiva de sustentabilidade para o setor do audiovisual. Avista-se, então, que o FSA amplia o fomento público direto para o setor, promovendo uma relação mais articulada entre produtores e exibidores, o que permitirá, para um futuro próximo, equilibrar a aplicação dos recursos de terceiros a partir do mecanismo de renúncia fiscal.

Quanto à Lei 12.485, promulgada em setembro de 2011, espera-se é que haja uma ampliação da demanda de produção de conteúdo audiovisual nacional e independente, dinamizando a cadeia produtiva como um todo, sobretudo por meio do mecanismo de cotas de exibição obrigatórias. Com a integralização de tecnologias, Também se almeja estabelecer uma maior democratização do acesso à comunicação audiovisual de acesso condicionado (TVs por Assinatura), a partir do aumento da concorrência entre as operadoras do segmento, promovendo um crescimento do número de assinantes e uma diminuição do preço desses serviços.Verifica-se que, com a nova lei, o Estado passa a atuar em conjunto com outros agentes do mercado audiovisual, havendo uma ampliação dos investimentos para o setor, que passa a contar com recursos advindos do Orçamento Geral da União, além de outras fontes como o CONDECINE, visto que tais recursos serão destinados ao FSA para que este efetive novas linhas de atuação. Com as cotas, intenta-se incentivar a criação de canais e programadoras brasileiras, além de propulsionar a produção de conteúdo nacional, como filmes, séries, documentários e animação. Abrem-se possibilidades para se exportar conteúdo nacional, assim como também se estimula a conexão entre programadores, produtores de conteúdo e emissoras de TV, gerando demanda de roteiristas, diretores, produtores, atores e atrizes, técnicos, bem como de infraestrutura e outros componentes da cadeia produtiva do audiovisual. É notável que o FICA expressa o crescimento da produção audiovisual local e nacional, podendo ser observado, por exemplo, por meio do aumento gradativo das produções nacionais e regionais inscritas para a Mostra Competitiva Oficial do festival, bem como atesta o quadro abaixo. 
Tabela 3. Mostra competitiva oficial

\begin{tabular}{|c|c|c|}
\hline no & $\begin{array}{c}\text { Obras Nacionais } \\
\text { Inscritas }\end{array}$ & $\begin{array}{c}\text { Obras Goianas } \\
\text { Inscritas }\end{array}$ \\
\hline $\mathbf{0 0 1}$ & 17 & 7 \\
\hline $\mathbf{0 0 2}$ & 100 & 9 \\
\hline $\mathbf{0 0 5}$ & 200 & 34 \\
\hline $\mathbf{0 0 8}$ & 208 & 48 \\
\hline $\mathbf{0 0 9}$ & 265 & 54 \\
\hline
\end{tabular}

Dados do site oficial do FICA

Frente a esse contexto, percebe-se que há um grande interesse do Estado brasileiro, bem como da iniciativa privada, em concretizar uma indústria audiovisual de caráter sustentável, segundo Da-Rin (2010, p.91)

[...) não só pela crescente circulação de imagens em nossa época, pelo alto valor econômico envolvido e pela necessidade imperiosa de uma nação dominar sua autorrepresentação simbólica. Parte da infraestrutura imaterial de um povo, sua cinematografia contribui para, no plano interno, gerar entre os cidadãos o sentimento de pertencimento na comunidade nacional e, no externo, difundir os valores culturais do país e abrir espaços diplomáticos e comerciais.

O FICA, que no ano de 2013 entra em sua 15a edição, atravessou todos esses marcos, consolidando-se regional, nacional e internacionalmente. Desse modo, observa-se que a ideia geral do festival, seus condicionantes, sua estrutura e seu perfil estão antenados às demandas da economia criativa, considerando a importância que essa nova perspectiva de desenvolvimento está tomando. 


\section{O Festival Internacional de Cinema e Vídeo Ambiental (FICA) e a economia criativa}

\section{Considerações finais}

O objetivo deste trabalho foi realizar um estudo sobre o Festival Internacional de Cinema e Vídeo Ambiental, buscando visualizá-lo a partir do prisma da economia criativa. Primeiramente, a intenção foi identificar as ações do festival e distingui-las quanto à suas características fundamentais, ficando constatada a capacidade do evento em unir o formal e o informal. Foi observado também, que parte das ações realizadas todos os anos, tem como base as tecnologias da informação, somando possibilidades ao repertório cinematográfico, ambiental, cultural e social goiano, combustível do evento. Em função desse conjunto de ações, o festival aciona (incentiva) iniciativas que se fundamentam na inventividade, nos saberes tradicionais, em caracteres específicos da cultura, etc.

Em sua primeira edição, o FICA custou $\mathrm{R} \$ 1$, , fatura igualmente dividida entre iniciativas pública e privada. Já em 2012, o governo de Goiás anunciou o investimento de quatro milhões de reais para o festival, o que demonstra uma valorização significativa do evento. Ressalte-se, ainda, que nos últimos dois anos, o festival passou também por modificações específicas, não só estruturais, mas administrativas, sobretudo no que se refere à descentralização das ações, o que garantiu uma maior autonomia cultural e valorizou os talentos dos profissionais envolvidos na produção do evento. Quanto à preservação e à valorização da diversidade cultural, pode-se dizer que o FICA oferece um grande diferencial, ao elencar elementos e personalidades que compõem a memória e a identidade goianas para compor seus quadros de referência. Cabe ressaltar que o festival oferece, todos os anos, uma programação diversificada de expressões culturais, entre música, teatro, dança, vídeo, artesanato, pintura, fotografia. Assim, o FICA combina diversidade cultural e abundância dos recursos naturais, considerando a exuberância da vegetação, dos rios e da geografia, próprios à cidade de Goiás.

Destarte, para uma aproximação mais significativa com as diretrizes desse novo modelo de desenvolvimento, um dos primeiros obstáculos a ser enfrentado pelo festival é a falta de pesquisas e geradores de índices, mapeamentos e dados acerca dos setores criativos, suas extensões e suas limitações, seus profissionais e suas competências. A ausência dessas informações dificulta a proposição adequada de ações e políticas de incentivo, formação, produção, circulação e difusão dos produtos e serviços criativos locais. Outro desafio refere-se à falta de interdisciplinaridade institucional, que hoje no Brasil, representa uma enorme barreira para a economia criativa. É possível afirmar que as ações do FICA são ainda muito incipientes quanto à integração e convergência entre instituições, tendo em vista a amplitude e potencial do festival. Contudo, algumas iniciativas já apresentam resultados favoráveis, sobretudo aquelas realizadas por meio do Empório SEBRAE FICA de Cinema e Vídeo. Dessa forma, Empório representa um dos avanços mais expressivos do festival quanto ao exercício da transversalidade, 
aproximando diversos setores e contribuindo não só com a formação e o nivelamento dos profissionais e a circulação dos produtos, como também com a regularização legal dos empreendimentos.

Por fim, o grande desafio da sustentabilidade está imposto, não havendo meios de contorná-lo sem causar grandes desgastes sociais, culturais e ambientais. Mesmo se valendo do simbólico como combustível fundamental, a economia criativa ainda demanda meios e recursos físicos, por exemplo, para tornar as expressões culturais, os saberes tradicionais etc., produtos vendáveis. Nesse sentido, criar estratégias para valorizar a diversidade cultural, contribuir para a qualidade de vida e causar menor impacto ambiental, é também um desafio nuclear do FICA. As duas últimas edições do festival demonstraram uma maior preocupação com a reciclagem dos resíduos sólidos, mas ainda nota-se a necessidade de um planejamento mais sério e urgente para minimizar os danos, considerando a especificidade temática do festival.

\section{Referências}

AGECOM - Agência Goiana de Comunicação. AGEPEL aumenta cachê para shows musicais no $13^{\circ}$ FICA. In: GOIÁS AGORA: Notícias do Estado de Goiás, 2011. Disponível em:

http://www.noticias.goias.gov.br/index.php?idMateria=104808\&tp = $\quad$ positivo $>$ Acesso em: 12 de dez. 2012.

BAHIA, Lia. Formação do Campo Audiovisual Brasileiro: Reflexões sobre a Relação entre Cinema e Televisão no Brasil. Estudos de cinema. Porto Alegre, $n^{\circ}$ 23, Famecos/PUCRS agosto 2010.

BLYTHE, Mark. The work of art in the age of digital reproduction: the significance of the creative industries. In: JADE, v. 20, n. 2, p. 144-150, 2001.

BRASIL. Ministério da Cultura. Plano da Secretaria da Economia Criativa: políticas, diretrizes e ações 2011 - 2014. Brasília, 2011. Disponível em: $<$ http://www.cultura.gov.br/site/wp-content/uploads/2011/09/Plano-da-Secretariada-Economia-Criativa.pdf> Acesso em: $10 \mathrm{de} \mathrm{dez.} 2012$.

BRASIL. Medida Provisória no 2.228-1, de 06 de setembro de 2001. Estabelece princípios gerais da Política Nacional de Cinema e dá outras providências. Diário Oficial [da] República Federativa do Brasil. Brasília, DF, 10 set. 2001. Disponível em <www.planalto.gov.br/ccivil_03/MPV/2228-1.htm>. Acesso em: 26 mar 2013.

BRASIL. Ministério do Turismo. Turismo Cultural: orientações básicas. Ministério do Turismo, Secretaria Nacional de Políticas de Turismo, Departamento de Estruturação, Articulação e Ordenamento Turístico, Coordenação-Geral de Segmentação. 3a ed, Brasília: Ministério do Turismo, 2010.

CARVAlHOSA, Zita (org.). Guia Brasileiro de Festivais de Cinema e Vídeo, 1999. São Paulo: Kinoforum/Canal Brasil, 1999. 


\section{O Festival Internacional de Cinema e Vídeo Ambiental (FICA) e a economia criativa}

CHAUL, Nasr Nagib Fayad. Caminhos de Goiás: da construção da decadência aos limites da modernidade. Goiânia: Editora da UFG, 1995.

DA-RIN, Silvio. Dez Anos de Políticas Públicas para o Audiovisual Brasileiro. Revista Observatório Itaú Cultural / OIC - n. 10 (set./dez. 2010). - São Paulo, SP: Itaú Cultural, 2010.

FÓRUM NACIONAL DOS ORGANIZADORES DE EVENTOS AUDIOVISUAIS. Diagnóstico setorial / 2007. Rio de Janeiro, 2008.

FÓRUM DOS FESTIVAIS. Diagnóstico Setorial 2007 / Indicadores 2006 dos Festivais Audiovisuais. Disponível em $<w w w$.forumdosfestivais.com.br $>$ Consulta em 26 mar de 2013.

FONSECA, Ana Carla. Economia Criativa - um novo olhar sobre o que faz a diferença. In: Plano da Secretaria da Economia Criativa: políticas, diretrizes e ações 2011 - 2014. Brasília, 2011. Disponível em: <http://www.cultura.gov.br/site/wpcontent/uploads/2011/09/Plano-da-Secretaria-da-Economia-Criativa.pdf $>$ Acesso em: 10 de dez. 2012.

HALL, Stuart. A identidade cultural na pós-modernidade. $11^{\mathrm{a}}$ ed, Rio de janeiro: DP\&A, 2006.

HARTLEY, John. Creative industries. London: Blackwell, 2005.

HELI, Espíndola. FICA 2012. In: Portal da Cultura, 2012. Disponível em: $<$ http://www.cultura.gov.br/culturaviva/FICA-2012> Acesso em: 12 de dez. 2012.

HOWKINS, John. The creative economy: How people make money from ideas. London: Penguin Press, 2001.

LEAL, Tetê; MATTOS, Antônio. Festivais Audiovisuais Brasileiros: Um Diagnóstico do Setor. V ENECULT - Encontro de Estudos Multidisciplinares em Cultura, 2009.

LIMA FILHO, Manuel Ferreira. O Futuro do Passado da Cidade de Goiás: Gestão, memória, identidade. In: Habitus: Revista do Instituto Goiano de Pré-História e Antropologia da Universidade Católica de Goiás. Goiânia, v.1, n.1, 2003.

REVISTA DO FESTIVAL INTERNACIONAL DE CINEMA E VÍDEO AMBIENTAL. Publicação Institucional: Governo de Goiás. Ano 2, n.1, 2011. Disponível em: <http://FICA.art.br/wp-content/uploads/2012/06/Revista1Edicao.pdf> Acesso em: 10 de dez. 2012.

SITE OFICIAL DO FICA. O Festival. Disponível em: <http://FICA.art.br/o-festival $>$ Acesso em: 12 de dez. 2012. 